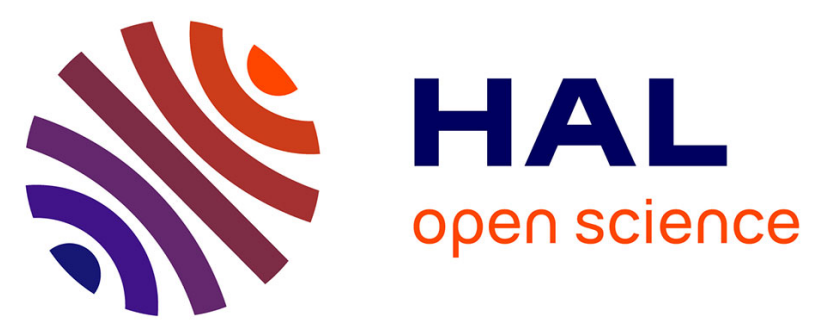

\title{
Identification of a Transient but Key Motif in the Living Coordinative Chain Transfer Cyclocopolymerization of Ethylene with Butadiene
}

Islem Belaid, Benoît Macqueron, Marie-Noëlle Poradowski, Samira Bouaouli, Julien Thuilliez, Fernande Da Cruz-Boisson, Vincent Monteil, Franck

D'agosto, Lionel Perrin, Christophe Boisson

\section{To cite this version:}

Islem Belaid, Benoît Macqueron, Marie-Noëlle Poradowski, Samira Bouaouli, Julien Thuilliez, et al.. Identification of a Transient but Key Motif in the Living Coordinative Chain Transfer Cyclocopolymerization of Ethylene with Butadiene. ACS Catalysis, 2019, 9 (10), pp.9298-9309. 10.1021/acscatal.9b02620 . hal-02319677

\section{HAL Id: hal-02319677 \\ https://hal.science/hal-02319677}

Submitted on 12 Nov 2020

HAL is a multi-disciplinary open access archive for the deposit and dissemination of scientific research documents, whether they are published or not. The documents may come from teaching and research institutions in France or abroad, or from public or private research centers.
L'archive ouverte pluridisciplinaire HAL, est destinée au dépôt et à la diffusion de documents scientifiques de niveau recherche, publiés ou non, émanant des établissements d'enseignement et de recherche français ou étrangers, des laboratoires publics ou privés. 


\title{
Identification of a transient but key motif in the living coordinative chain transfer cyclo-copolymerization of ethylene with butadiene
}

\author{
Islem Belaid, ${ }^{\ddagger}$ a Benoit Macqueron, ${ }^{\ddagger, a}$ Marie-Noëlle Poradowski, ${ }^{b}$ Samira Bouaouli, ${ }^{\text {J Julien Thuil- }}$ \\ liez, ${ }^{\mathrm{c}}$ Fernande Da Cruz-Boisson, ${ }^{\mathrm{d}}$ Vincent Monteil, ${ }^{\mathrm{a}}$ Franck D’Agosto, ${ }^{\mathrm{a}}$ Lionel Perrin, ${ }^{\mathrm{b},{ }^{*} \text { Chris- }}$ \\ tophe Boisson $^{\mathrm{a},{ }^{*}}$ \\ a Univ Lyon, Université Claude Bernard Lyon 1, CPE Lyon, CNRS UMR 5265, Laboratoire de Chimie Catalyse Po- \\ lymères et Procédés ( $\mathrm{C}_{2} \mathrm{P}_{2}$ ), Equipe LCPP, Bat 308F, 43 Bd du 11 Novembre 1918, F-69616 Villeurbanne, France \\ ${ }^{\mathrm{b}}$ Université de Lyon, Université Claude Bernard Lyon 1, CPE Lyon, INSA Lyon, ICBMS, CNRS UMR 5246, Equipe \\ ITEMM, 43 Bd. du 11 Novembre 1918, 69622 Villeurbanne, France \\ ' MFP Michelin, 23 Place des Carmes Dechaux, 63040 Clermont-Ferrand, France d Univ Lyon, INSA de Lyon, CNRS, \\ IMP UMR 5223, F-69621 Villeurbanne, France
}

\begin{abstract}
Copolymers of ethylene and butadiene were prepared using the ansa-bisfluorenyl $\mathrm{Me}_{2} \mathrm{Si}\left(\mathrm{C}_{13} \mathrm{H} 8\right)_{2} \mathrm{NdR}$ complex in combination with dialkylmagnesium as a chain transfer agent. Thorough kinetic studies and computational mechanistic investigations of this copolymerization reaction were performed. Combined with detailed analyses of the polymer microstructure and chain-ends, these studies demonstrate that the entitled copolymerization operates according to a living coordinative chain transfer copolymerization of ethylene and butadiene. Besides, in addition to the formation of the previously described 1,2-cyclohexane inner chain cyclic motif, the presence of bicyclic 1,5-decalin units via the formation of transient vinylcyclohexyl-methyl chain-end is discussed in the present communication. The non-accumulation of the vinylcyclohexane motif within the chains is explained by the reversibility of its formation, as interpreted with the help of DFT calculations, or by its rapid conversion into decalin motif after one ethylene insertion. Finally, this study also illustrates the ability of the fluorenyl ligand to adjust its binding mode on demand in order to avoid inhibition of catalyst.
\end{abstract}

KEYWORDS: ethylene; butadiene; cyclo-copolymerization; mechanism; cyclohexane-unit; decalin-unit

\section{INTRODUCTION}

Olefins and conjugated dienes are readily available monomers. The copolymerization of these two classes of monomers is particularly attractive since it provides a wide range of polyolefins bearing unsaturated groups and possibly intra-chain rings. ${ }^{1}$ Nevertheless, the copolymerization of olefins with conjugated dienes is a difficult challenge as the copolymerization of these two monomers requires distinct catalysts and polymerization conditions. Indeed, group 4 metallocenes, which are highly active towards olefin polymerization, have shown a dramatic decrease in activity in the presence of butadiene together with a low butadiene insertion. Efficient copolymerization catalysts have only recently been developed. ${ }^{1}$ Depending on the polymer composition, thermoplastics or elastomers are produced. The microstructure of the inserted butadiene units depends on the regio- and stereoselectivity of butadiene insertion leading to internal cis or trans double bonds as well as vinyl ramifications. ${ }^{2-6}$ Rings in the resulting copolymers of ethylene and butadiene are formed by intramolecular cyclization involving vinyl units. Cyclopropane and cyclopentane ${ }^{7-9}$ rings have been obtained with group 4 metallocene catalysts while cyclohexane rings have been obtained with neodymium metallocene catalysts. ${ }^{10-14}$ Since then, the selectivity for ring formation has been investigated computationally at the DFT level. ${ }^{15}$ Lanthanide metallocenes have shown an unprecedented efficiency for the copolymerization of olefins with conjugated dienes. ${ }^{2,11,16,17}$ More recently, cationic half sandwich scandium catalysts have been used for the copolymerization of olefin and conjugated dienes providing copolymers with novel microstructures. ${ }^{18-20}$ In our seminal contributions, we have prepared new elastomers obtained by copolymerization of ethylene and butadiene with the complex $\left\{\mathrm{Me}_{2} \mathrm{Si}\left(\mathrm{C}_{13} \mathrm{H}_{8}\right)_{2} \mathrm{Nd}\left(\mathrm{BH}_{4}\right)_{2} \mathrm{Li}(\text { thf })\right\}_{2}$ used in presence of $(n \mathrm{Bu})(n \mathrm{Oct}) \mathrm{Mg}$ (BOMAG) as an alkylating agent. These elastomers were named EBR for Ethylene Butadiene Rubbers and they contain trans-1,4-butadiene, vinylbutadiene and 1,2-cyclohexane units. ${ }^{10,14}$

In the case of the homopolymerization of ethylene mediated by a lanthanidocene, the dialkylmagnesium not only acts as an alkylating agent but also as a chain transfer agent. ${ }^{21-24}$ The fast and reversible chain transfer between neodymium and magnesium leads to the formation 
of dipolyethylenylmagnesium by Coordinative Chain Transfer Polymerization (CCTP). ${ }^{25-29}$ In the course of our investigations, ${ }^{10}$ we have suggested that BOMAG is also a chain transfer agent during the copolymerization of ethylene and butadiene mediated by Nd-based catalysts. In this communication, we demonstrate that BOMAG does act as a reversible chain transfer agent. Considering the complexity of the microstructure of the EBR obtained with the $\left\{\mathrm{Me}_{2} \mathrm{Si}\left(\mathrm{C}_{13} \mathrm{H}_{8}\right)_{2} \mathrm{Nd}\left(\mathrm{BH}_{4}\right)_{2} \mathrm{Li}(\text { thf })\right\}_{2} /$ BOMAG catalytic system, a diversity of chain-ends can be obtained and potentially transferred to magnesium. This makes the understanding of the mechanism of cyclocopolymerization of ethylene and butadiene performed under CCTP conditions more complex. Thereof, in the present work, we report a detailed investigation of the kinetics and chain transfer reaction involved in the cyclocopolymerization of ethylene and butadiene, and we streamline the key-role in controlling the polymerization reaction played by the formation of unprecedented unit in the copolymers.

\section{RESULTS AND DISCUSSION}

Kinetics and evolution of molar masses with productivity are investigated for the cyclo- copolymerization of ethylene with butadiene catalyzed by $\left\{\mathrm{Me}_{2} \mathrm{Si}\left(\mathrm{C}_{13} \mathrm{H}_{8}\right)_{2} \mathrm{Nd}\left(\mathrm{BH}_{4}\right)_{2} \mathrm{Li}(\text { thf })\right\}_{2}$ / BOMAG system. Two sets of experiments were performed using a feed of 5 and $20 \mathrm{~mol} \%$ of butadiene and various $[\mathrm{Mg}] /[\mathrm{Nd}]$ concentration ratios. Aliquots were regularly withdrawn from the polymerization medium. The productivity is obtained by measuring the concentration of polymer $\left(\mathrm{g} \mathrm{L}^{-1}\right)$ of the aliquots. Collected samples were then further analyzed by size exclusion chromatography (SEC). Figures 1 and 2 show the evolution of productivity with time. The productivity increases linearly with time when using 20 mol\% of butadiene in the feed showing a stable activity. Regarding polymerizations performed with $5 \mathrm{~mol} \%$ of butadiene, a stable activity is obtained at elevated $[\mathrm{Mg}] /[\mathrm{Nd}]$ ratios (20 and 40). Kinetics are merely impacted by the concentration of magnesium when the feed contains $20 \mathrm{~mol} \%$ of butadiene.

In the case of ethylene homopolymerization, it has been observed that the higher the $[\mathrm{Mg}] /[\mathrm{Nd}]$ ratio, the lower the apparent $k_{\mathrm{p}}\left(k_{\mathrm{p}}{ }^{\mathrm{app}}\right)$. This behavior was interpreted on the basis of an equilibrium between the active metallocene that is dissociated from the chain transfer agent, and a dormant heterobimetallic species. ${ }^{21}$ Thereof, an increase in magnesium concentration leads to a decrease in active species concentration and of $k_{\mathrm{p}}^{\text {app. In other }}$ words, the energetic cost of the dissociation of the dormant heterobimetallic species contributes to the overall energy barrier for ethylene insertion. ${ }^{21}$

Computational mechanistic investigations have also shown that butadiene insertion in the Nd- allyl intermediate formed after butadiene insertion is not a limiting kinetic step for the $\left\{\mathrm{Me}_{2} \mathrm{Si}\left(\mathrm{C}_{13} \mathrm{H}_{8}\right)_{2} \mathrm{Nd}\left(\mathrm{BH}_{4}\right)_{2} \mathrm{Li}(\text { thf })\right\}_{2}$ / BOMAG catalytic system. ${ }^{15}$ Hence, we assume that the formation of the metal-alkyl and metal-allyl species from ethylene or butadiene insertions respectively does not limit the rate of polymerization. In order to fully explain the kinetic profiles of this cyclo-copolymerization, we have considered the reactivity of the intermediates formed after intramolecular cyclization (vide infra).

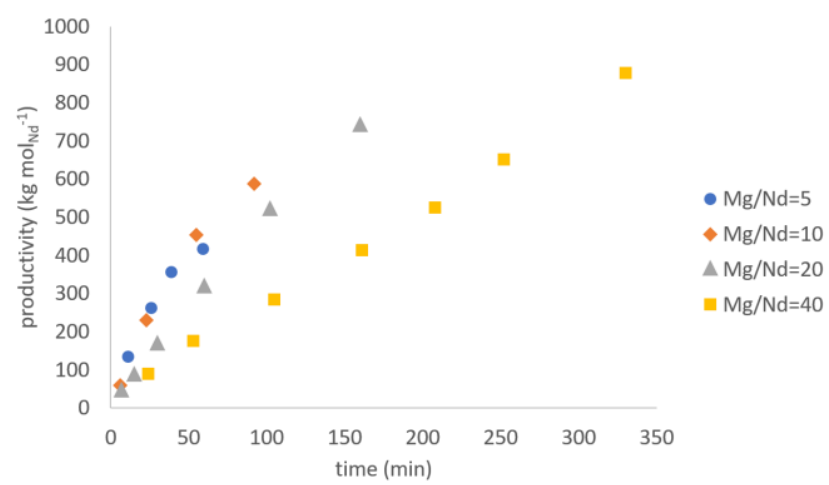

Figure 1. Evolution of productivity vs. polymerization time at different $[\mathrm{Mg}] /[\mathrm{Nd}]$ concentration ratios for a feed containing $5 \mathrm{~mol} \%$ of butadiene.

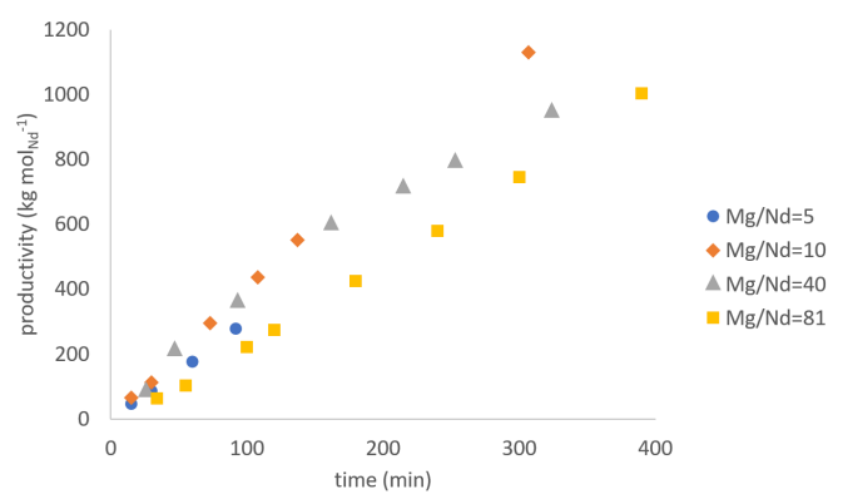

Figure 2. Evolution of productivity vs. polymerization time at different $[\mathrm{Mg}] /[\mathrm{Nd}]$ concentration ratios for a feed containing $20 \mathrm{~mol} \%$ of butadiene.

In order to assess the livingness of the copolymerization of ethylene and butadiene with $\left\{\mathrm{Me}_{2} \mathrm{Si}\left(\mathrm{C}_{13} \mathrm{H}_{8}\right)_{2} \mathrm{Nd}\left(\mathrm{BH}_{4}\right)_{2} \mathrm{Li}(\text { thf })\right\}_{2} /$ BOMAG catalyst, the evolution of the number-average molar masses has been plotted vs. productivity in Figures 3 and 4 (see also Tables $\mathrm{S}_{1}$ and $\mathrm{S}_{2}$ in ESI). For all the polymerizations, the number-average molar masses linearly increase with productivity in agreement with a pseudo-living polymerization. Figure 5 shows a smooth increase in molar masses for a $[\mathrm{Mg}] /[\mathrm{Nd}]$ concentration ratio of 40 . However, the number of chains per magnesium is lower than the theoretical value of two for which each alkyl group initiates a polymer chain at the beginning of polymerization, but tends towards this value upon polymerization. Note that 1.6 to 1.8 chains per magnesium are obtained with a feed containing $5 \mathrm{~mol} \%$ of butadiene at elevated $[\mathrm{Mg}] /[\mathrm{Nd}]$ ratios.

These results are consistent with a relatively low chain transfer constant to BOMAG resulting in a time delay required to balance the set of equilibria between active and dormant organometallic species. Additionally, a broadening of molar mass distribution has been observed 
for some high molar mass sample (up to 2.3). This phenomenon has been ascribed to an increase in viscosity in the polymerization medium as part of the reaction medium stuck on the reactor wall. In conclusion, the observed linear increase of molar masses with productivity and the number of chains per magnesium are consistent with a polymerization operating according to a degenerative chain transfer between $\mathrm{Mg}$ and $\mathrm{Nd}$ centers. To our knowledge, this is the first demonstrated example of coordinative chain transfer co-polymerization of ethylene and butadiene.

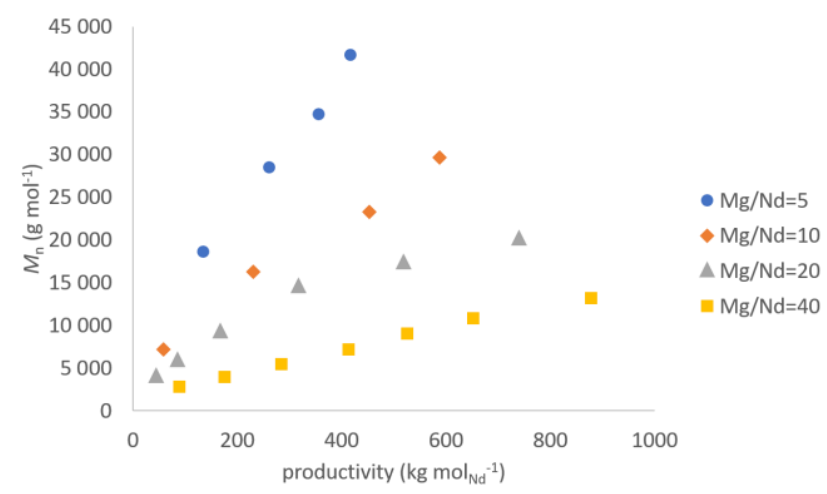

Figure 3. Evolution of number-average molar masses with productivity at different $[\mathrm{Mg}] /[\mathrm{Nd}]$ concentration ratio for a feed containing $5 \mathrm{~mol} \%$ of butadiene.

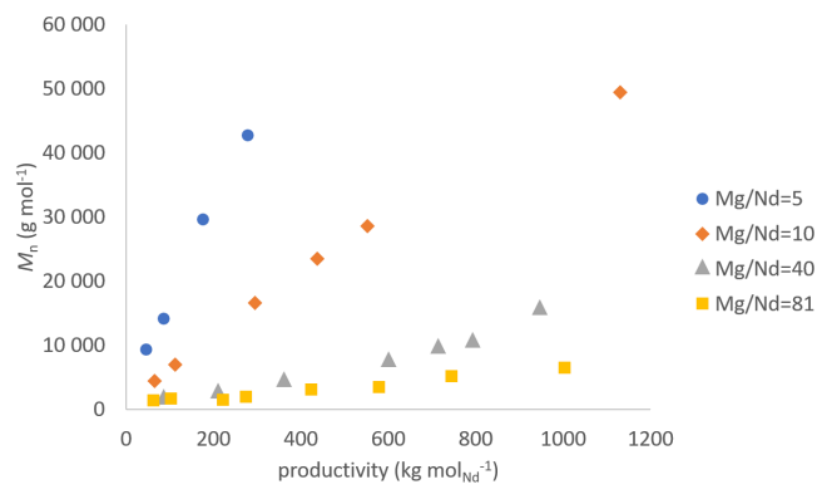

Figure 4. Evolution of number-average molar masses with productivity at different $[\mathrm{Mg}] /[\mathrm{Nd}]$ concentration ratios for a feed containing $20 \mathrm{~mol} \%$ of butadiene.

Under the polymerization conditions, most of the resulting copolymer chains are bound to Mg centers. As already demonstrated for ethylene homopolymerization,,$^{30}$ the reactivity of the polymer-Mg bound is a very valuable tool to both assess the livingness of the chains and produce end-functionalized reactive polyolefins. In the case of cyclo-copolymerization of ethylene and butadiene, the identification of the chain end motif can bring additional and valuable information on the selectivity of the exchange reaction between $\mathrm{Nd}$ and $\mathrm{Mg}$ with respect to the nature of the last co-monomer inserted. A copolymer of low molar mass was prepared at 4 bars and $70^{\circ} \mathrm{C}$ using a $[\mathrm{Mg}] /[\mathrm{Nd}]$ concentration ratio of $8 \mathrm{o}$ and a butadiene feed of $20 \mathrm{~mol} \%$ (Table $\mathrm{S}_{3}$ ). A fraction of the polymerization medium was deactivated with methanol leading to copolymer 1 and the remaining fraction with iodide in order to functionalize the copolymer with an iodo group providing copolymer 2. Chain-ends of these copolymers were investigated by ${ }^{1} \mathrm{H}$ and ${ }^{13} \mathrm{C}$ NMR in $\mathrm{CDCl}_{3}$ at $300 \mathrm{~K}$ (Figure $6, \mathrm{~S} 1$ and $\mathrm{S}_{2}$ ).
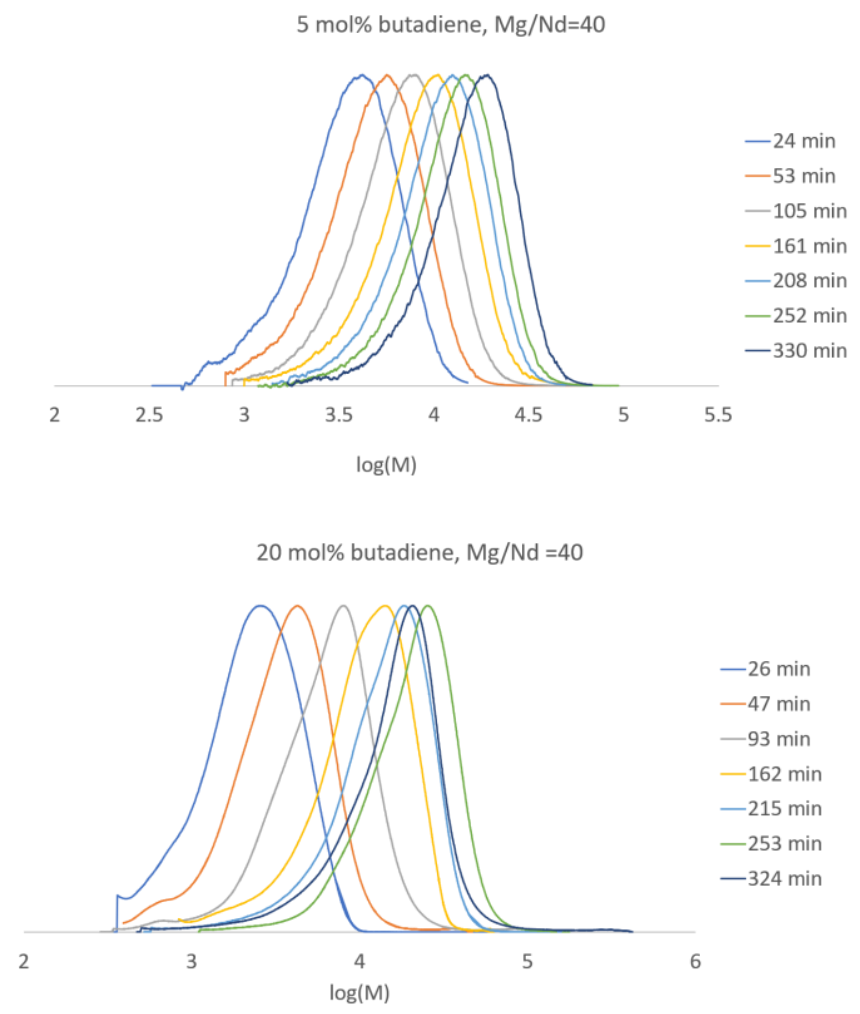

Figure 5. Evolution of number average molar mass with polymerization time at $[\mathrm{Mg}] /[\mathrm{Nd}]$ concentration ratio of 40 and for a feed containing $5 \mathrm{~mol} \%$ (top) and $20 \mathrm{~mol} \%$ (down) of butadiene.

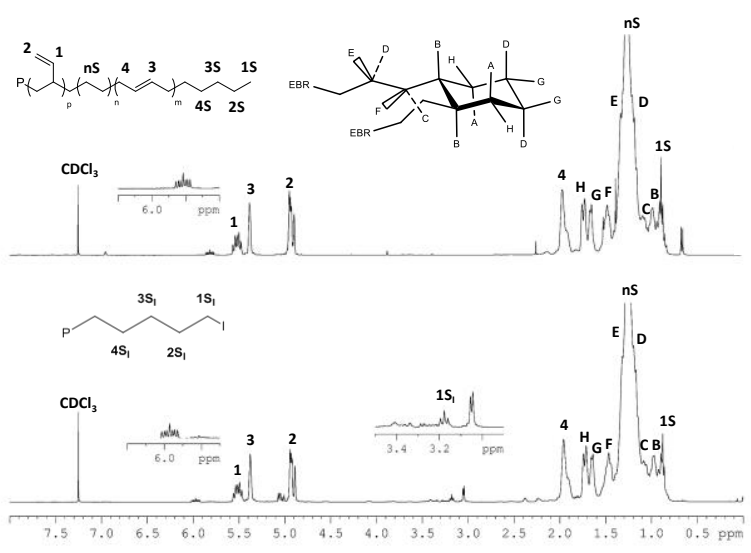

Figure 6. ${ }^{1} \mathrm{H}$ NMR spectrum of poly(ethylene-co-butadiene) prepared with $\left\{\mathrm{Me}_{2} \mathrm{Si}\left(\mathrm{C}_{13} \mathrm{H}_{8}\right)_{2} \mathrm{Nd}\left(\mathrm{BH}_{4}\right)_{2} \mathrm{Li}(\text { thf })\right\}_{2} /$ BOMAG (top - copolymer 1 ) and ${ }^{1} \mathrm{H}$ NMR spectrum of iodo functionalized poly(ethylene-co-butadiene) prepared with $\left\{\mathrm{Me}_{2} \mathrm{Si}\left(\mathrm{C}_{13} \mathrm{H}_{8}\right)_{2} \mathrm{Nd}\left(\mathrm{BH}_{4}\right)_{2} \mathrm{Li}(\text { thf })\right\}_{2} /$ BOMAG (bottom - copolymer 2) $\left(\mathrm{CDCl}_{3}\right.$, $\left.300 \mathrm{~K}\right)$.

${ }^{1} \mathrm{H}$ NMR spectra of copolymers 1 and 2 (Figure 6) show characteristics resonances of ethylene, trans-1,4butadiene, 1,2-butadiene and cyclohexane units., ${ }^{2,11}$ Methyl chain ends are observed (terminal methyl $1 \mathrm{~S}$ ) at $0.88 \mathrm{ppm}$ 
and no signals of vinyl chain ends could be detected in the region between 4.5 and $6.5 \mathrm{ppm}$. This means that no $\beta$-H elimination, nor transfer to monomers, occurs during the copolymerization. This agrees with the pseudo-living character of this polymerization. Compared to the ${ }^{1} \mathrm{H}$ NMR spectrum already recorded for high molar mass copolymers obtained under the same conditions (Figure $\mathrm{S}_{3}$ ), the ${ }^{1} \mathrm{H}$ NMR spectrum of copolymer 1 shows two intense signals at 0.65 (doublet) and $5.81 \mathrm{ppm}$ (multiplet)

These resonances, which are hardly detectable for a copolymer of higher molar masses, can be assigned to chain end protons. Indeed, the spectrum of the iodo endfunctionalized copolymer 2 shows a shift of the signals at 5.81 up to $5.97 \mathrm{ppm}$. An overlapped signal with that of vinyl units in copolymer 1 at ca 4.90 is also shifted to 5.04 ppm. In addition, the almost complete disappearance of the signal at $0.65 \mathrm{ppm}(\mathrm{J}=7 \mathrm{~Hz})$ is observed and additional resonances between 3.0 and 3.5 ppm are now visible. The resonances between 3.0 and 3.5 ppm correspond to protons close to the iodo group introduced on the chain end of copolymer 2. In particular, a doublet appears at $3.05 \mathrm{ppm}(\mathrm{J}=5 \mathrm{~Hz})$. Signals at $3.05 \mathrm{ppm}, 5.04 \mathrm{ppm}$ and 5.97 are ascribed to an unexpected chain end. Besides, the 1:2 relative intensity of the signals at 5.97 and $5.04 \mathrm{ppm}$ in the spectrum of copolymer 2 is consistent with the presence of a vinyl group on this terminal motif. The accurate determination of the chain ends in both copolymers 1 and 2 required a thorough NMR analysis that was performed with the help of ${ }_{10}{ }^{13} \mathrm{C}$ NMR and ${ }_{2} \mathrm{D}-{ }^{1} \mathrm{H} /{ }^{1} \mathrm{H}$ COSY and TOCSY and ${ }_{2} \mathrm{D}^{-1} \mathrm{H} /{ }^{13} \mathrm{C}$ HSQC and HMBC experiments. The corresponding spectra are collected and fully assigned in Figures $\mathrm{S}_{5}$ to S8. Chain-end structures featuring vinylcyclohexyl-methyl moiety depicted in Scheme 1 could then be proposed.
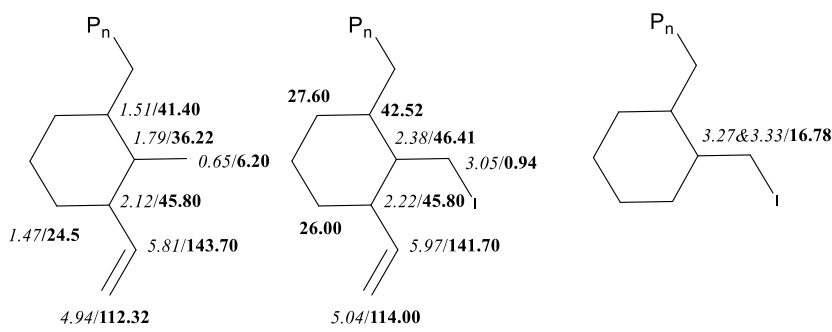

Scheme 1. Chemical structures and chemical shift assignments for vinylcyclohexyl-methyl, vinylcyclohexyliodo-methyl and cyclohexyl-iodo-methyl chain-ends found in copolymers 1 and 2 prepared with $\left\{\mathrm{Me}_{2} \mathrm{Si}\left(\mathrm{C}_{13} \mathrm{H}_{8}\right)_{2} \mathrm{Nd}\left(\mathrm{BH}_{4}\right)_{2} \mathrm{Li}(\text { thf })\right\}_{2} /$ BOMAG (proton chemical shifts in italics, carbon chemical shifts in bold).

Concerning other chain-ends, the well-resolved triplet at $3.18 \mathrm{ppm}$ in copolymer 2 can be assigned to protons in $\mathrm{CH}_{2}-\mathrm{CH}_{2}-\mathrm{I}$ consistently with chains having an ethylene terminal unit. ${ }^{31}$ The HSQC spectrum shows the correlation of two doublets at 3.27 and 3.33 ppm with a methylene carbon at $16.78 \mathrm{ppm}$ (Figure $\mathrm{S}_{4}$ ). These signals are ascribed to a cyclohexyl-iodo-methyl terminal group (Scheme 1). In addition, ${ }^{13} \mathrm{C}$ NMR spectrum of copolymer 1 does not feature any signals corresponding to vinyl (-
$\left.\mathrm{CH}=\mathrm{CH}_{2}\right)$ or vinylene $\left(-\mathrm{CH}=\mathrm{CH}-\mathrm{CH}_{3}\right)$ chain-end. Eventually, chain ends corresponding to the functionalization of terminal allyl bond with iodide are not detected in copolymer 2 (expected chemical shifts at $3.78 \mathrm{ppm}$ ). This result supports the absence of allyl-terminated chains shuttling from $\mathrm{Nd}$ to $\mathrm{Mg}$ centers, as previously reported. ${ }^{15}$

A mechanism for the formation of these vinylcyclohexyl-methyl groups is proposed in Scheme 2. This results in the formation of copolymer chain exhibiting the already reported microstructure ${ }^{11}$ and alkyl, cyclohexyl-methyl and vinylcyclohexyl-methyl chain-ends. Considering the rather high proportion of terminal vinylcyclohexyl-methyl in copolymer 1 and the corresponding vinylcyclohexyliodo-methyl chain-ends in copolymer 2 , the presence of vinyl-cyclohexane units in the backbone of high molar mass copolymers of ethylene and butadiene could be expected. However, this motif has not been detected in the polymer chain so far. The detailed investigation of the ${ }^{13} \mathrm{C}$ NMR spectrum of a high molar mass copolymer (composition of $18.2 \%$ of butadiene, $20.6 \%$ of trans-1,4, $40.5 \%$ of vinyl, $39.0 \%$ of 1,2-cyclohexane, $\mathrm{Mn}=50,000 \mathrm{~g} \mathrm{~mol}^{-1}$ and $Đ=1.50$ ) does not show intense signals remaining unassigned (Figure 7). In particular, only trans-1,4 and vinyl butadiene units are detected in the unsaturated region of the spectrum. Consequently, no other unit bearing a vinyl group such as a vinyl-cyclohexane appears to be present in the copolymer backbone. In the saturated region of the spectrum, signals corresponding to vinyl units resulting from the insertion of butadiene in 2,1 manner, trans-1,4 units as well as the typical trans-1,2cyclohexane rings are assigned. Furthermore, sequences of the constitutive units of the copolymer (VEV, VEE, TEV, VET, TEE, TET, TT, etc... these notations are defined in Figure 7 and correspond to those adopted by Llauro et al. ${ }^{11}$ ) were carefully ascribed. We also assigned signals corresponding to trans-1,4-cyclohexane and cis1,2-cyclohexane rings that were observed and previously assigned by our group in the case of copolymerization of ethylene and butadiene mediated by the $\left[\mathrm{Me}_{2} \mathrm{Si}\left(2,7^{-}\right.\right.$ $\left.\left.\mathrm{tBu}_{2} \mathrm{C}_{13} \mathrm{H}_{6}\right)_{2} \mathrm{Nd}\left(\mathrm{BH}_{4}\right)_{2} \mathrm{Li}(\text { ether })_{3}\right]$ complex. ${ }^{14}$ However, a closer inspection of the corresponding ${ }^{13} \mathrm{C}$ NMR spectrum reveals the presence of small and yet unassigned resonances. Indeed, signals with comparable low intensities are observed at 20.30, 24.97, 28.42 and $42.51 \mathrm{ppm}$. The latter signal corresponds to a $\mathrm{CH}$ group. Nevertheless, the complexity of the ${ }^{13} \mathrm{C}$ NMR does not permit to ascribe these signals to vinyl-cyclohexane units. In addition, we estimate that these signals correspond to the presence of an unknown structure (vide infra) and not to a vinylcyclohexane unit since no new vinyl moiety is observed as mentioned above. Due to the enhanced steric hindrance induced by the vinylcyclohexyl-methyl terminal group towards further monomer insertion, we assume that the reactivity of this intermediate is a rate limiting step of the copolymerization reaction. To further comprehend the mechanism of formation of this peculiar moiety and its subsequent reactivities, computational mechanistic studies were undertaken. 


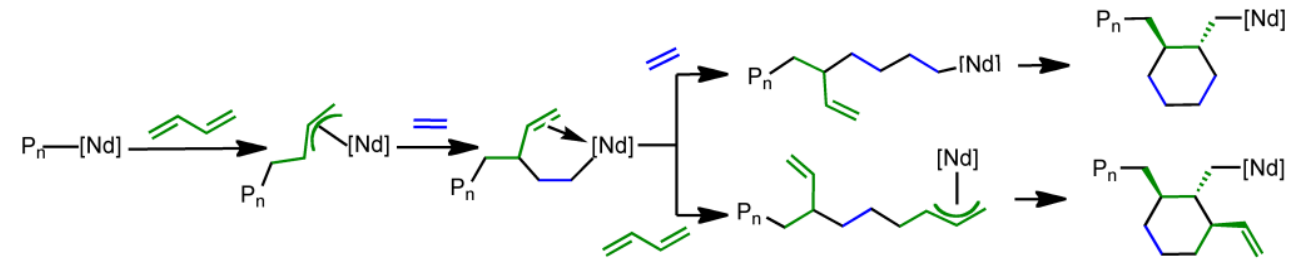

Scheme 2. Proposed mechanism for the formation of cyclohexyl-methyl and vinylcyclohexyl-methyl moieties.

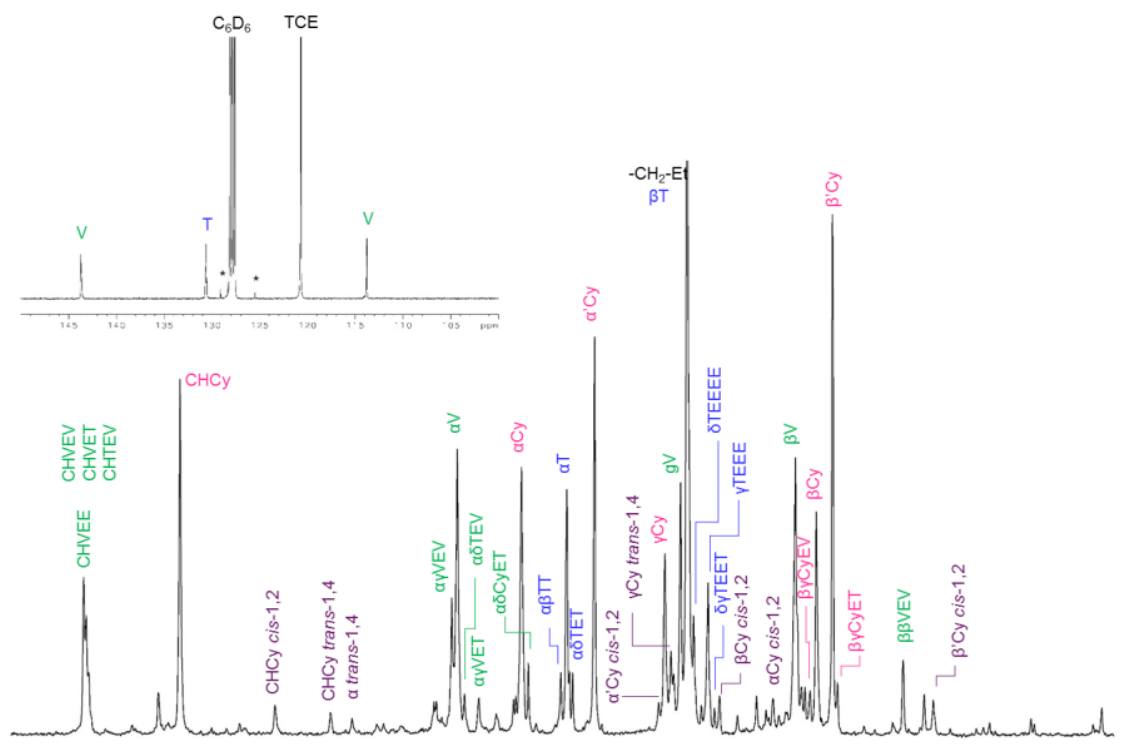

$\begin{array}{lllllllllllllllllllllllll}45 & 44 & 43 & 42 & 41 & 40 & 39 & 38 & 37 & 36 & 35 & 34 & 33 & 32 & 31 & 30 & 29 & 28 & 27 & 26 & 25 & 24 & 23 & 22 & \mathrm{ppm}\end{array}$

Figure 7. Assignment of main structures in a high molar mass poly(ethylene-co-butadiene) prepared with $\left\{\mathrm{Me}_{2} \mathrm{Si}\left(\mathrm{C}_{13} \mathrm{H}_{8}\right)_{2} \mathrm{Nd}\left(\mathrm{BH}_{4}\right)_{2} \mathrm{Li}(\text { thf })\right\}_{2} /$ BOMAG $\left(\mathrm{TCE} / \mathrm{C}_{6} \mathrm{D}_{6} 2 / 1 \mathrm{v} / \mathrm{v}, 363 \mathrm{~K}\right)$. The notation corresponds to that used by Llauro et al." $(\mathrm{E}$ stands for inserted ethylene units, $\mathrm{T}$ for trans-1,4 inserted butadiene units, $\mathrm{V}$ for butadiene units inserted in 2,1 manner and $\mathrm{Cy}$ for the cycles, residual toluene signals are assigned with an asterisk).

For these studies, we have used the computational approach and methodology depicted in our previous communications regarding the modeling of polymerization reactions mediated by neodymocene complexes under chain exchange conditions enabled by a dialkylmagnesium as chain transfer agent. ${ }^{15,21}$ The fully detailed computational procedures are available in the ESI.

In summary, the hybrid functional $\mathrm{B}_{3} \mathrm{PW}_{91}$ and the basis set $6-311 \mathrm{G}(d, p)$ have been used for $\mathrm{C}, \mathrm{H}$ and $\mathrm{O}$ atoms. The same basis set, augmented by diffuse functions, has been used for $\mathrm{Mg}$. Si is represented by a pseudo relativistic ECP in association with its polarized basis set. 11electrons large core RECP in association with its polarized basis set has been used to represent the lanthanide center. This computational level has shown to offer a good compromise between accuracy and computational cost for studying the reactivity of lanthanide (III) complexes, $15,21,32,33$ and has been intensively used by Perrin, Maron, and Eisenstein in mechanistic studies involving lanthanide III complexes. ${ }^{34-37}$ In the present study, solvation (SMD-toluene) has been considered by default during optimization, as well as dispersion as a single point $\mathrm{D}_{3}-\mathrm{BJ}$ empirical correction. $15,21,33$
As a structural model, growing chains are considered to contain at least four carbon atoms in order to avoid spurious artifacts. ${ }^{3}$ Dialkylmagnesium has been explicitly included in the chemical model as depicted in our previous communication. ${ }^{15,21}$ The experimental catalyst

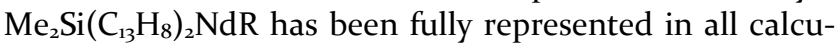
lations. Thermal and entropy contributions have also been included by means of frequency calculation within the harmonic approximation. The potential electronic surface has been explored by hand, considering as much as realistic conformers as possible, however no automated conformational search procedure has been used. Only the most stable conformers are reported. In addition, most insertion selectivities have been tested; for each step, profiles of the two lowest energy pathways are at least depicted.

Before exploring the energy landscape of monomer insertions, the absence of allyl shuttling from $\mathrm{Nd}$ to $\mathrm{Mg}$ centers raised our attention. In order to model this chain exchange reaction, that is formally a transmetalation between [Mg]-alkyl and [Nd]-allyl sites, we have considered $\mathrm{Me}_{2} \mathrm{Si}\left(\mathrm{C}_{13} \mathrm{H}_{8}\right)_{2} \mathrm{Nd}\left(\eta^{3}-\mathrm{C}_{3} \mathrm{H}_{5}\right)$ and $\mathrm{Mg}_{4} \mathrm{Bu}_{8}$ to represent $[\mathrm{Nd}]$-allyl and [Mg]-alkyl sites, respectively. Thermody- 
namically, starting from $[\mathrm{Nd}]\left(\eta^{3}-\mathrm{C}_{3} \mathrm{H}_{5}\right)$ and $\mathrm{Mg}_{4} \mathrm{Bu}_{8}$, the allyl/alkyl exchange to form [ $\mathrm{Nd}] \mathrm{Bu}$ is endergonic by 11.6 kcal mol-1 as shown in Figure 8. However, association of the $[\mathrm{Nd}] \mathrm{Bu}$ active site with a magnesium cluster according to Equation $\mathrm{A}$ leads to an overall exergonic balance of $4.6 \mathrm{kcal} \mathrm{mol}^{-1}$. Hence the transfer of allyl site from the catalyst to the chain transfer agent is not limited thermodynamically but kinetically. Thereof, we explored the reaction pathways leading to this exchange reaction.

$$
\begin{aligned}
{[\mathrm{Nd}]\left(\eta^{3}-\mathrm{C}_{3} \mathrm{H}_{5}\right) } & +3 / 2 \mathrm{Mg}_{4} \mathrm{Bu}_{8} \\
& =[\mathrm{Nd}] \mathrm{Mg}_{2} \mathrm{Bu}_{5}+\mathrm{Mg}_{4} \mathrm{Bu}_{7}\left(\mathrm{C}_{3} \mathrm{H}_{5}\right)
\end{aligned}
$$

First of all, no single alkyl/allyl group exchange mechanism could be identified. In addition to the catalyst-chain transfer agent association/dissociation steps, characterized by transition states TS $^{1}$ and TS $^{3}$ (Figure 8), the reaction proceeds via successive and complex rearrangements in bridging heterobimetallic species. The complexity of the mechanism results from the versatility of the binding modes of the allyl ligand within polymetallic clusters and the floppiness of the potential energy surface, as illustrated by selected bimetallic intermediates $\mathbf{B M}^{1}$ to $\mathbf{B M}^{7}$ whose energies range from $-2.1 \mathrm{kcal} \mathrm{mol}^{-1}$ to $7 \mathrm{kcal} \mathrm{mol}^{-1}$ with respect to the reactant (Figure 8). In order to illustrate the overall shape of the potential energy surface, the scan from $\mathbf{B M}^{1}$ to $\mathbf{T S}^{3}$ is provided in the ESI (Figure S9). Among the transition states, only the one corresponding to the transfer of the allyl group from $\mathrm{Nd}$ to $\mathrm{Mg}\left(\mathbf{T S}^{2}\right)$ was properly converged. However, according to the set of intermediates optimized, two successive steps are at least needed to fulfill the sliding of the allyl group from $\mathrm{Nd}$ to
Mg. In $\mathbf{B M}^{1}$ the bridging allyl group is $\eta^{3}$ coordinated to $\mathrm{Nd}$ and $\eta^{1}$ coordinating to $\mathbf{M g}$, while in $\mathbf{B M}^{7}$ this same group is $\mu-\eta^{1}-\eta^{1}$ with respect to $\mathrm{Mg}$ and $\eta^{1}$ with respect to $\mathrm{Nd}$. Concerning the transfer of the alkyl chain, it can proceed either by rotation of the chain or inversion of configuration as indicated by the different orientations of the lone pair at $\mathrm{C}^{1}$ (see $\mathbf{B M}^{2}, \mathbf{B M}^{3}$ and $\mathbf{B M}^{\mathbf{6}}$ on Figure 8).

Though we were not able to fully depict this chain shuttling mechanism, we were able to capture the step that account for the absence of allyl shuttling from $\mathrm{Nd}$ to $\mathrm{Mg}$. It corresponds to the dissociation of the Mg-allyl group from the lanthanide fragment. The energy barrier for this step has been computed at $21 \mathrm{kcal} \mathrm{mol}^{-1}$, i.e. 3 to $6 \mathrm{kcal}$ $\mathrm{mol}^{-1}$ more than monomer insertion barriers (see section below and Figure 8). This apparently results from the release of the unsaturated [Nd]-Bu site. According to this mechanism, the $[\mathrm{Nd}]$-allyl site also reversibly binds the chain transfer agent to form slightly more stable bimetallic complexes such as $\mathbf{B M}^{\mathbf{1}}$ but cannot fulfill site exchange or chain exchange as the [Nd]-alkyl site does. This association between the [Nd]-allyl site and the chain transfer agent merely impacts the energy profile of insertion and will not be included in the following section that account for the exploration of monomer insertion mechanism and selectivities.

For convenience, insertion sequences are letter coded. For minima, the last letter gives the nature of the active site: E for alkyl site, B for allyl site and C for alkyl site generated after cyclization. The other letters track the history of insertions. Insertion of monomer into the $\mathrm{Nd}$ $\mathrm{C}^{2}$ bond of a $\mathbf{B}$ site yields to a ${ }^{21} \mathbf{B}$ unit and insertion into the $\mathrm{Nd}-\mathrm{C}^{4}$ bond to a ${ }^{\mathrm{t}} 4 \mathbf{B}$ unit (Figure 9).

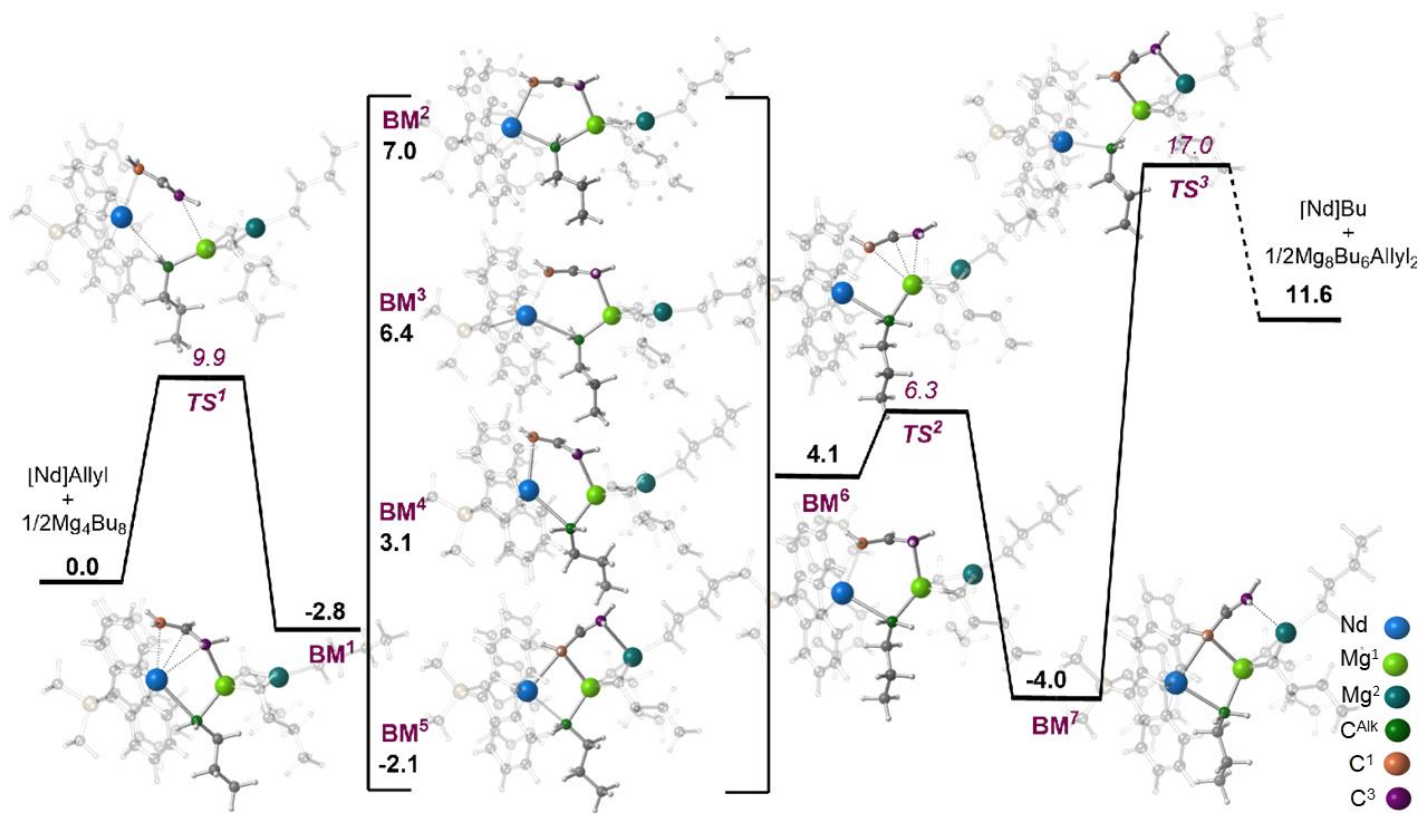

Figure 8. Free energy profile for the allyl/alkyl exchange between $\mathrm{Nd}$ and $\mathrm{Mg}$ centers. For the sake of clarity, only the atoms implied in the exchange are highlighted, remaining atoms are shadowed. Gibbs energies ( 1 atm, $298 \mathrm{~K})$ are relative to $\mathrm{Me}_{2} \mathrm{Si}\left(\mathrm{C}_{13} \mathrm{H}_{8}\right)_{2} \mathrm{Nd}\left(\eta 3-\mathrm{C}_{4} \mathrm{H}_{7}\right)$ and $\mathrm{Mg}_{4} \mathrm{Bu}_{8}$. 


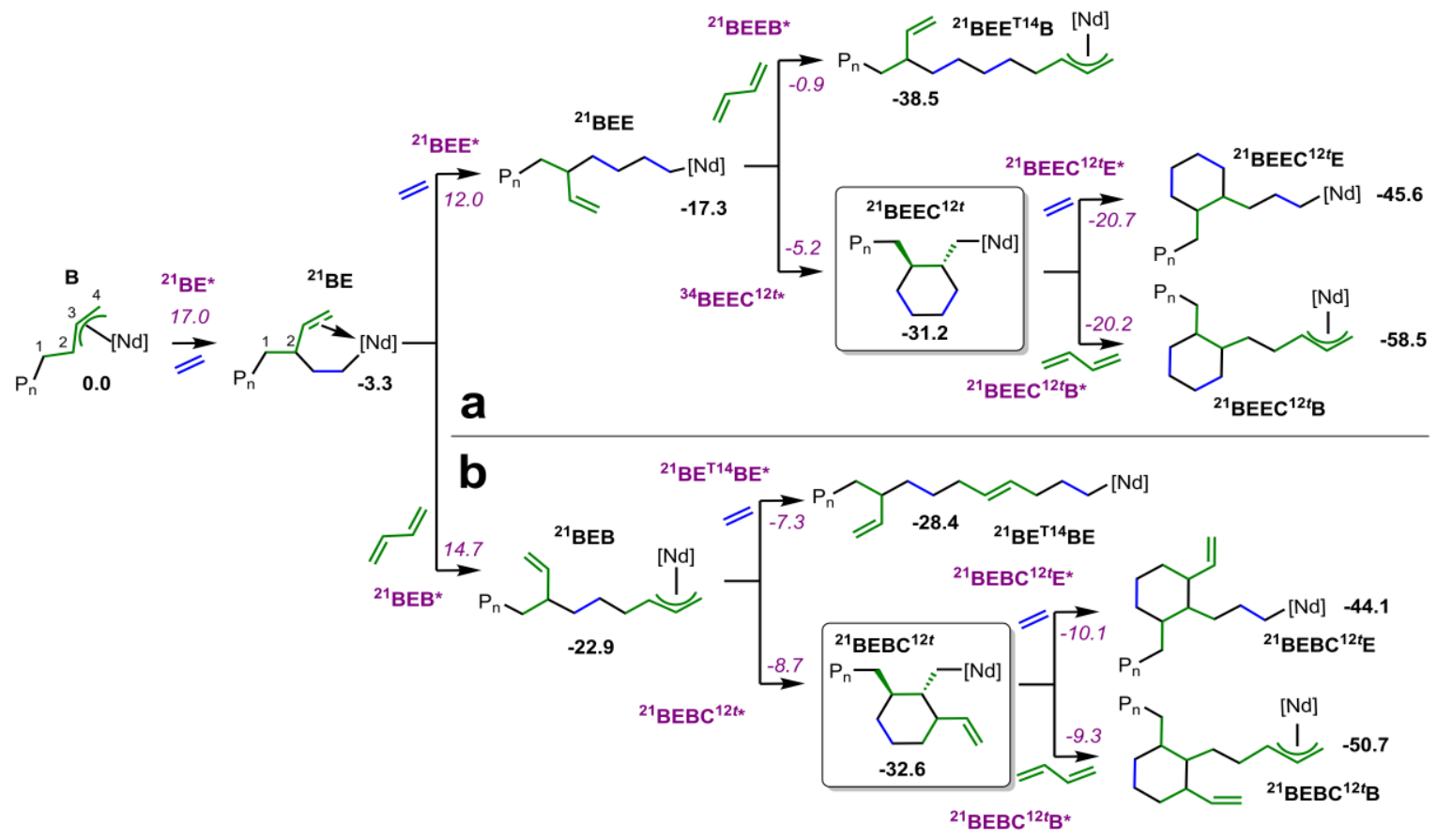

Figure 9. Mechanisms and energetics for the formation of di- (panel a) and tri-substituted (panel b) cyclohexane units. Gibbs energies $(1 \mathrm{~atm}, 298 \mathrm{~K})$ are relative to $\mathrm{Me}_{2} \mathrm{Si}\left(\mathrm{C}_{13} \mathrm{H}_{8}\right)_{2} \mathrm{Nd}\left(\eta^{3}-\mathrm{C}_{4} \mathrm{H}_{7}\right) \mathrm{B}\left([\mathrm{Nd}]=\mathrm{Me}_{2} \mathrm{Si}\left(\mathrm{C}_{13} \mathrm{H}_{8}\right)_{2} \mathrm{Nd}\right)$, ethylene and butadiene and are given in kcal mol-1. Energies of transition states are in italic violet, energies of minima are in bold black. $\mathrm{P}_{\mathrm{n}}=\mathrm{H}$.

Insertion of ethylene is labeled $\mathbf{E}$. Cyclizations are labeled $\mathbf{C}$ and the numbers after $\mathbf{C}$ define the regio- and stereo-chemistry of the ring formed. Adduct of a monomer to an active site is labeled with an underscore between the active site and the monomer to be inserted (e.g., E_E adduct of ethylene to an alkyl site). Transition states (TS) are identified with an asterisk after the inserted monomer (e.g., EE* ethylene insertion TS into an alkyl site). As previously shown, ${ }^{10,11,15}$ the sequence by which cyclohexane units are formed starts from the migratory insertion of ethylene (transition state ${ }^{2 \mathbf{1}} \mathbf{B E}^{*}$, Figure 9, panel a) in a Nd-allyl site that is modeled here by $[\mathrm{Nd}]\left(\eta^{3}-\right.$ $\left.\mathrm{C}_{4} \mathrm{H}_{7}\right) \mathbf{B},[\mathrm{Nd}]=\mathrm{Me}_{2} \mathrm{Si}\left(\mathrm{C}_{13} \mathrm{H}_{8}\right)_{2} \mathrm{Nd}$.

Starting from complex ${ }^{2 \mathbf{1}} \mathbf{B E}$, insertion of ethylene is kinetically the most favorable with an associated transition state ${ }^{21} \mathbf{B E E}^{*}$ at $\mathbf{1 2 . 0} \mathrm{kcal} \mathrm{mol}^{-1}$ above the reactants and afford the precursor of 1,2-cyclohexane unit ${ }^{21}$ BEE. The kinetics of this intramolecular cyclization is favored by 4.3 kcal mol-1 over the most favorable intermolecular insertion of butadiene whose ${ }^{21} \mathbf{B E E B}^{*}$ transition state lies at $0.9 \mathrm{kcal} \mathrm{mol}^{-1}$ relative to the initial allyl complex B. As shown by the small energy difference of $0.5 \mathrm{kcal} \mathrm{mol}^{-1}$ between transition states ${ }^{21} \mathbf{B E E C}^{12 t} \mathbf{E}^{*}$ and ${ }^{21} \mathbf{B E E C}^{12 t} \mathbf{B}^{*}(12 t$ refers to a 1,2-trans-cyclohexane ring), both butadiene and most likely ethylene undergo insertion after cyclization.

The sequence by which the tri-substituted vinylcyclohexyl-methyl- moiety is formed differs from the previously described sequence by the 1,4 insertion of butadiene (transition state ${ }^{21} \mathbf{B E B}^{*}$ ) instead of ethylene (transition state $^{21} \mathbf{B E E}^{*}$ ) before cyclization (Figure 9, panel b). At this point, insertion of butadiene only requires $2.7 \mathrm{kcal} \mathrm{mol}^{-1}$ more than the insertion of ethylene and is thus likely to occur during polymerization. Then, intramolecular cyclization to offer the ${ }^{21} \mathbf{B E B C}{ }^{12 t}$ requires $14.2 \mathrm{kcal} \mathrm{mol}^{-1}$ to proceed and is kinetically more favored than ethylene insertion by $1.4 \mathrm{kcal} \mathrm{mol}^{-1}$. Though the presence of the additional vinyl ramification raises the steric demand on the metallocene active site, the formation of the trisubstituted cyclohexane unit is almost as exergonic as the formation of the di-substituted cyclohexane unit. Moreover, the coordination of the vinyl ramification by the metal center brings additional stability to the Nd complex, as the product of cyclization ${ }^{\mathbf{2}} \mathbf{B E B C} \mathbf{C}^{\mathbf{1 2 t}}$ is thermodynamically more stable than the product of ethylene insertion ${ }^{21} \mathrm{BE}^{\mathrm{T}} 14 \mathrm{BE}$ by $4.2 \mathrm{kcal} \mathrm{mol}^{-1}$.

Though the kinetics and thermodynamics associated to the formation of di- and tri-substituted cyclohexane motifs are similar, their post reactivity towards ethylene or butadiene insertion significantly differs. Indeed, whereas insertions of ethylene and butadiene at ${ }^{21} \mathbf{B E E C}^{\mathbf{1 2 t}}$ respectively require 10.5 and $11.0 \mathrm{kcal} \mathrm{mol}^{-1}$ to proceed, insertions of these two monomers at the bulky ${ }^{21} \mathbf{B E B C} \mathbf{1}^{\mathbf{1 2 t}}$ site kinetically require ca. $12 \mathrm{kcal} \mathrm{mol}^{-1}$ more. This trend can be explained by the rigid coordination of the vinyl ramification to the metal center and suggests that for this catalytic system, a second monomer cannot assist the insertion of a first one. 39

The representation of the $3 \mathrm{D}$ structure of ${ }^{21} \mathbf{B E E C}^{\mathbf{1 2 t}}$ and ${ }^{21} \mathbf{B E B C}{ }^{22 t}$ and of the subsequent ethylene insertion transition states ${ }^{21} \mathbf{B E E C}^{\mathbf{1 2 t}} \mathbf{E}^{*}$ and ${ }^{21} \mathbf{B E B C} \mathbf{C}^{\mathbf{1 2} \mathbf{E}} \mathbf{E}^{*}$ are shown in Figure 10. Whereas the disubstituted cyclohexyl site and the subsequent ethylene insertion transition state show typical geometries for the front-side insertion into an alkyl site, ${ }^{21,34}$ ethylene insertion into the trisubstituted cyclohexyl site shows significant distortion. First of all, in the 
complex ${ }^{21} \mathbf{B E B C}{ }^{12 t}$, the $\eta$-system of the vinyl interaction is clearly in interaction with the $\mathrm{Nd}$ center as indicted with distances of 3.11 / $3.13 \AA$ that are shorter by $0.3 \AA$ than those computed for the $\eta^{2}$-ethylene adduct to $\mathrm{Me}_{2} \mathrm{Si}\left(\mathrm{C}_{13} \mathrm{H}_{8}\right)_{2} \mathrm{NdBu}$ or in ${ }^{21} \mathbf{B E E C { } ^ { 1 2 t }}{ }_{-} \mathbf{E}^{21}$ This strong coordination has consequences on the acidity of the metal that is decreased by $0.08 \mathrm{e}$ between ${ }^{21} \mathbf{B E E C}^{12 t}$ and ${ }^{21} \mathrm{BEBC}^{12 \mathrm{t}}$, as indicated by the natural population analysis (NPA) of these two complexes. The influences of the coordination of the vinyl ramification in ${ }^{21} \mathbf{B E B C}{ }^{12 t}$ are magnified at the transition state of ethylene.

Comparison of the geometries of ${ }^{21} \mathbf{B E E C}^{12 t} \mathbf{E}^{*}$ and ${ }^{21} \mathbf{B E B C}^{12 \mathrm{t}} \mathbf{E}^{*}$ shows that, in the case of the tri-substituted cyclohexyl motif, the insertion of the incoming monomer induces a haptotropic rearrangement of one fluorenyl group from an $\eta^{3: 2}$ to an exocyclic- $\eta^{3}$ mode ( $\eta^{\text {3exo }}$ ) (Figure 10 and Figure Sio in ESI). This suggests that the fluorenyl ligand is more labile and adaptive than the heavily constrained vinyl ramification. In addition, the distances that are characteristic of the ethylene insertion shows that transition state ${ }^{21} \mathbf{B E B C} \mathbf{C}^{12 t} \mathbf{E}^{*}$ is late relative to transition state ${ }^{21} \mathbf{B E E C} \mathbf{C}^{12 t} \mathbf{E}^{*}$.

Remarkably enough, the competitive transition states for cyclization ${ }^{21} \mathbf{B E B C}^{12 \mathrm{t} *}$ and for ethylene insertion ${ }^{21} \mathbf{B E B C}^{12 t} \mathbf{E}^{*}$ that control the occurrence of the trisubstituted units in the polymers only differ by $1.4 \mathrm{kcal}$ $\mathrm{mol}^{-1}$ (Gibbs energy value). Thereof, the formation of the trisubstituted cyclohexane ring can be seen as reversible. Due to this equilibrium, transition states ${ }^{21} \mathbf{B E B E}^{*}$ and ${ }^{21} \mathbf{B E B C}^{12 t} \mathbf{E}^{*}$ become interlinked, and their Gibbs energies only differ by $2.8 \mathrm{kcal} \mathrm{mol}^{-1}$, these two pathways are competitive. Interestingly, in ${ }^{21} \mathbf{B E B C} \mathbf{C}^{12 t} \mathbf{E}$ a 6-heptenyl-Nd scaffold (Figure 11, ${ }^{21} \mathbf{B E B C}^{12 t} \mathbf{E}$ bold bonds) is formed and can potentially be subject to intramolecular cyclization leading to an unprecedented decalin polymer unit. This hypothesis has been explored computationally.

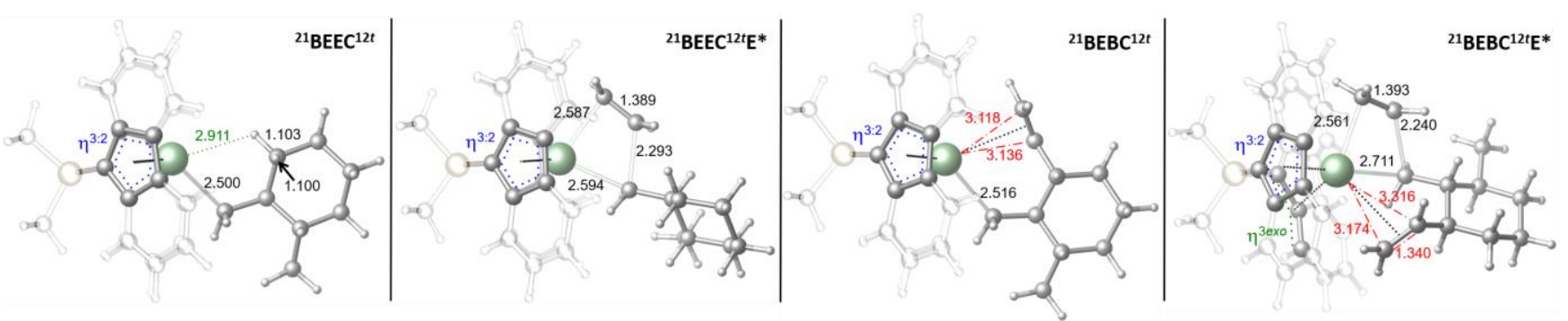

Figure 10. Representation of the $3 \mathrm{D}$ structures of the di- and tri-substituted cyclohexylmethyl active sites ${ }^{2 \mathbf{B}} \mathbf{B E E C} \mathbf{C}^{\mathbf{1 2 t}}$ and ${ }^{2 \mathbf{B}} \mathbf{B E B C} \mathbf{C}^{\mathbf{2} t}$ as well as the subsequent transition states for ethylene insertion. Distances in $\AA$. The $\eta^{3: 2}$ binding mode refers to an $\eta^{5}$-like interaction between the neodymium center and the cyclopentadienyl group. However, the carbon atoms of the cyclopentadienyl group are not involved in the same way in this interaction as in a $\eta^{5}$ binding mode.

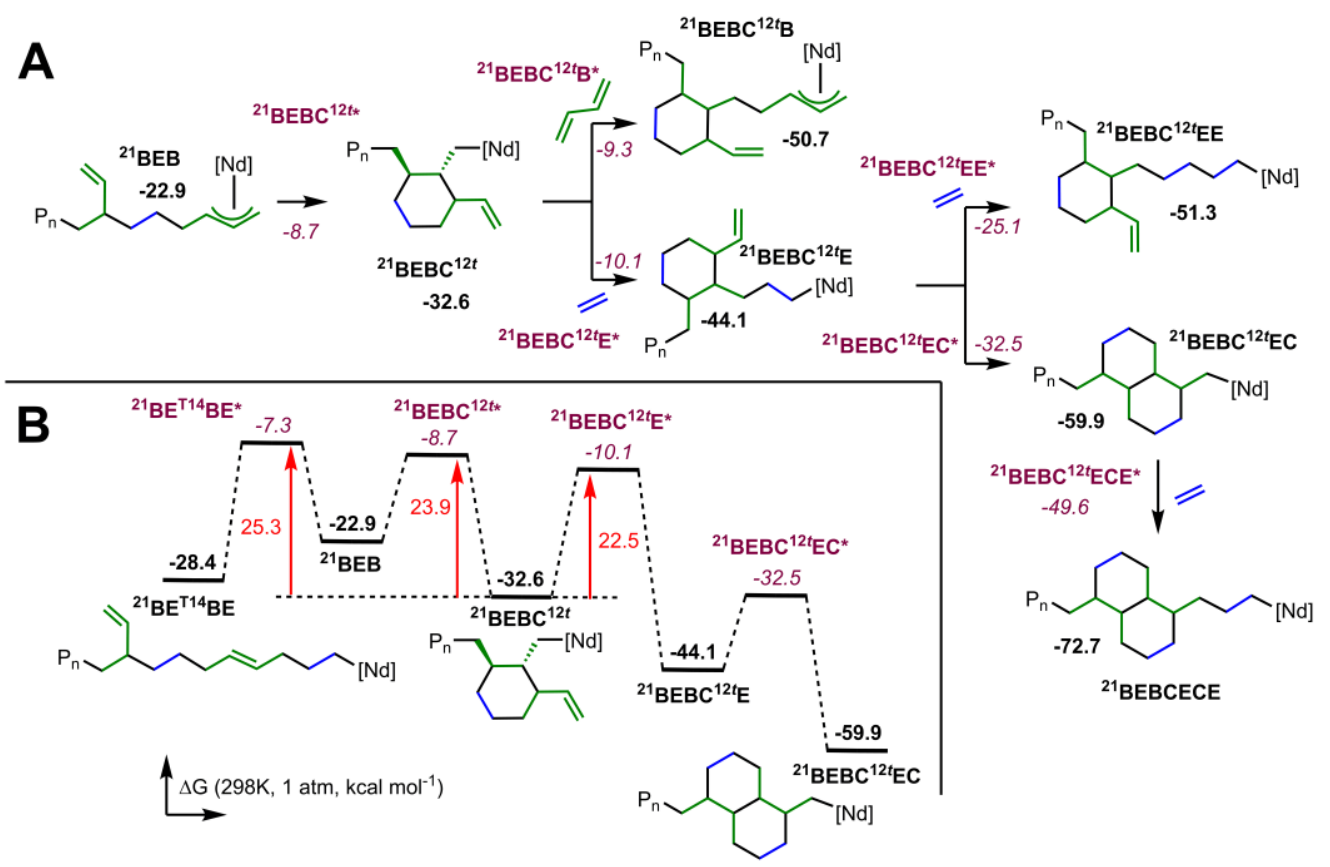

Figure 11. Mechanisms and energetics for the formation and the post-reactivity of tri-substituted cyclohexane- and decalin units: (A) profile as a reaction sequence; (B) energy profile for the reversible formation of tri-substituted cyclohexane unit. Gibbs energies are relative to $\mathrm{Me}_{2} \mathrm{Si}\left(\mathrm{C}_{13} \mathrm{H}_{8}\right)_{2} \mathrm{Nd}\left(\eta^{3}-\mathrm{C}_{4} \mathrm{H}_{7}\right) \mathrm{B}\left([\mathrm{Nd}]=\mathrm{Me}_{2} \mathrm{Si}\left(\mathrm{C}_{13} \mathrm{H}_{8}\right)_{2} \mathrm{Nd}\right)$, ethylene and butadiene and are given in kcal mol ${ }^{-1}$. Energies of transition states are in italic violet, energies of minima are in bold black. Red values are relative to the tri-substituted site ${ }^{21} B E B C{ }^{12 t}$. $P_{n}=H$. 


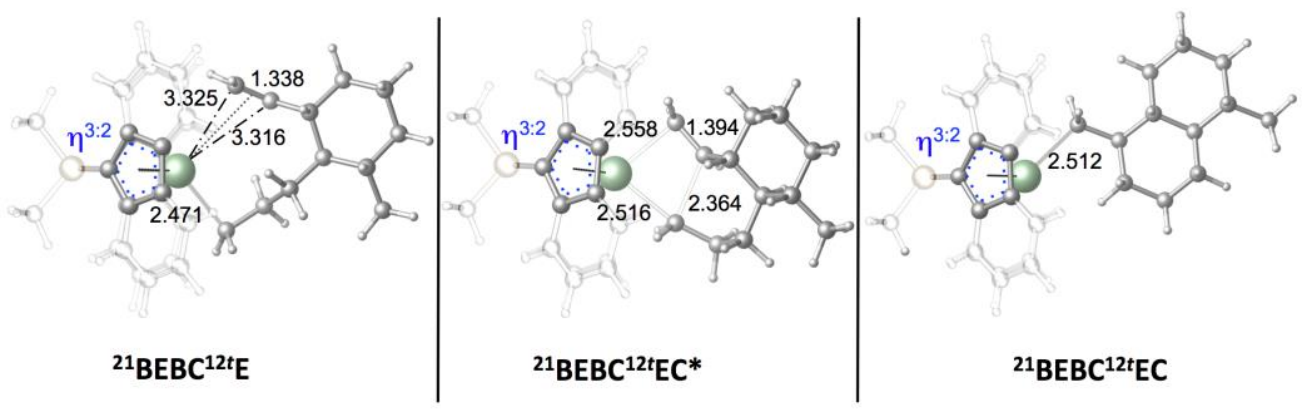

Figure 12. Representation of the 3D structure of the complexes involved in the formation of the decalin unit. Distances in $\AA$.

After ethylene insertion at the tri-substituted methylvinyl-cyclohexyl site ${ }^{21} \mathbf{B E B C}^{\mathbf{1 2 t}}$, intramolecular cyclization

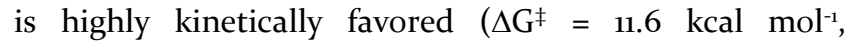
${ }^{21} \mathbf{B E B C}^{12 t} \mathbf{E C}^{*}$ ) over ethylene insertion as indicated by a difference of transition Gibbs energy of $7.4 \mathrm{kcal} \mathrm{mol}^{-1}$. As shown in Figure 12, the most favorable configuration of the 1,5-disubstituted decalin units is all trans.

As this decalin motif is not substituted by a vinyl group, its reactivity towards insertion is similar to that of a disubstituted cyclohexane motif. Indeed, the barrier for ethylene insertion at this specific site is similar (10.5 vs 10.0 kcal mol-1) than for the insertion of ethylene after a 1,2-cyclohexane unit (Figure 8).

As shown in Figure 12, adduct ${ }^{21} \mathbf{B E B C} \mathbf{C}^{\mathbf{1 2}} \mathbf{E}$ and transition state ${ }^{21} \mathbf{B E B C}^{12 t} \mathbf{E C}^{*}$ almost display usual geometrical parameters for ethylene insertion into a [Nd]-alkyl site.21 Comparatively to the highly sterically encumbered trisubstituted cyclohexyl site, the decalin site appears as accessible as a trisubstituted cyclohexyl site. This is corroborated by its reactivity towards ethylene insertion.

Based on this experimental investigation, analyses were carried out in order to identify decalin units within the copolymers. As mentioned above, a punctilious assignment of all the ${ }^{13} \mathrm{C}$ NMR signals in the spectrum of a high molar mass copolymer has been carried out (Figure 7). A series of unassigned signals have been detected in particular at 20.30, 24.97, 28.42 and 42.51 ppm. Considering, the ${ }^{13} \mathrm{C}$ NMR spectrum of a 1,5-dialkyl-decalin simulated with ChemDraw (Figure S11), it appears that the chemical shift of observed signals fits with that of a decalin unit ( $\mathrm{CH}$ of decalin $(42.51 \mathrm{ppm})$, two $\mathrm{CH}_{2}$ of the ring at 20.30 and $24.97 \mathrm{ppm}$ and $\mathrm{CH}_{2}$ in $\alpha$-position of the decalin motif at $28.42 \mathrm{ppm}$ ). Nevertheless, it was not possible to definitively conclude that decalin units was present since the second methine possibly overlapped with that of methine signal of vinyl units was not detected.

In order to provide more information for the identification of the decalin motif in the copolymer backbone, the analysis of the copolymer by pyrolysis coupled with gas chromatography and mass spectrometry (Pyrolysis-GCMS) was envisaged (Figure S12). The chromatogram shows the presence of alkenes resulting from the decomposition of the linear sequences of the copolymer and of cyclohexane and cyclohexene molecules (absent in the case of a polyethylene - Figure $\mathrm{S}_{13}$ and Table $\mathrm{S}_{5}$ ) con- sistent with the presence of these rings in the polymer backbone (Table $\mathrm{S}_{4}$ in ESI). Interestingly, the analysis reveals a peak at 16.08 minutes whose mass spectrum corresponds to decalin (cis or trans). Thus, this result suggests the presence of the decalin motif in the copolymer. The peak intensity is small suggesting that decalin content in the copolymer is low. This explains the difficulties encountered to identify this motif by NMR and also underline the value added of the computational studies to the interpretation of the experimental data.

\section{CONCLUSION}

Copolymerization of ethylene with butadiene was performed using $\mathrm{Me}_{2} \mathrm{Si}\left(\mathrm{C}_{13} \mathrm{H}_{8}\right)_{2} \mathrm{Nd}\left(\mathrm{BH}_{4}\right)_{2} \mathrm{Li}($ thf $\left.)\right\}_{2} / \mathrm{BOMAG}$ catalyst. We have shown that this copolymerization system follows a coordinative chain transfer polymerization governed by a reversible degenerative chain transfer between $\mathrm{Nd}$ and $\mathrm{Mg}$ centers. The functionalization of the resulting Mg-bound copolymer chains was performed using iodine. This allowed the identification of peculiar vinyl-cyclohexyl-methyl chain-ends that have not been identified so far in these systems. The rather high content of these chain-ends drove us to identify 3-vinyl-1,2cyclohexane motif along the chains, yet in a vain attempt. DFT calculations further show that the formation vinylcyclohexyl-methyl site may either be reversible or lead to a decalin motif in the copolymer chain. The presence of this motif, that is suspected in the ${ }^{13} \mathrm{C}$ NMR spectrum of the corresponding copolymers, was shown by Pyrolysis GC-MS analyses of the copolymer. 1,2,3-trisubstituted cyclohexane and all trans 1,5-disubstituted decalin units are two additional motifs that have not been observed so far in the large panel of motifs already reported in the literature for the cyclo-copolymerization of ethylene and butadiene including vinyl, cis-1,4 or trans-1,4 butadiene, ${ }^{2-4}$ 1,2-cyclohexane, ${ }^{10-12}$ 1,4-cyclohexane, ${ }^{13,14}$ cyclo-pentane and -propane, ${ }^{-9}$ and 1,1- and 1,3 units. ${ }^{5,6}$

The reversible formation of the furtive 1,2,3trisubstituted cyclohexane unit is not only the key precursor of the decalin motif but bring additional control to the polymerization by adequately raising the gap between the kinetic window of chain shuttling and propagation. This polymerization scheme shares some similarities with some of the reversible-deactivation radical polymerization (RDRPs) techniques for which both reversible termination and transfer reactions can be simultaneously be 
involved to improve the control of the chain growth. ${ }^{40,41}$ Additionally, the analysis of the geometries of monomer insertion after the 1,2,3-trisubstituted cyclo-hexyl explains the crucial role played by the fluorenyl ligand by adjusting its hapticity $\left(\eta^{5}, \eta^{3: 2}\right.$ or $\left.\eta^{3 \mathrm{exo}}\right)$ to the steric demand and the saturation need of the metal center. ${ }^{42,43}$ Finally, the computational mechanistic investigation of the allyl/alkyl site exchange reveals that [Nd]-allyl sites bind dialkylmagnesium clusters. Further analysis of this interaction and its consequences on activities and selectivities are under progress and will be reported in due time.

\section{ASSOCIATED CONTENT}

\section{Supporting Information}

Supporting tables, figures and spectra, as well as the detailed computational procedures are available as supporting document (PDF). In addition, Cartesian coordinates and associated energies of all computed structures are available as a Mercury archive (XYZ). The following files are available free of charge.

\section{AUTHOR INFORMATION}

\section{Corresponding Author}

Christophe Boisson: christophe.boisson@univ-lyonı.fr; Lionel Perrin: lionel.perrin@univ-lyonı.fr

\section{Author Contributions}

The manuscript was written through contributions of all authors. All authors have given approval to the final version of the manuscript. $\ddagger$ These authors contributed equally.

\section{ACKNOWLEDGMENT}

The authors thank the Manufacture Française des Pneumatiques Michelin for support and useful discussions. They thank the NMR Polymer Center of Institut de Chimie de Lyon (FR5223), for assistance and access to the NMR facilities. Olivier Boyron and Manel Taam $\left(\mathrm{C}_{2} \mathrm{P}_{2}\right)$ are thanked for HT-SEC analyses. M.-N.P. and L.P. thank the CCIR of ICBMS and $\mathrm{P}_{2} \mathrm{CHP}$ of Université Lyon 1 for providing computational resources and technical support. The authors acknowledge Hajar Nsiri for the preliminary investigation of cyclopolymerization mechanisms. IB, CB and FDA thank the company SRA Instruments for access to a pyrolysis GC-MS device.

\section{REFERENCES}

(1) Belaid, I.; Monteil, V.; Boisson, C. Copolymerization of Ethylene with Conjugated Dienes. In Handbook of Transition Metal Polymerization Catalysts, $2^{\text {nd }}$ edition, John Wiley \& Sons, Hoboken, 2018, 161-192.

(2) Barbotin, F.; Monteil, V.; Llauro, M. F.; Boisson, C.; Spitz, R. First Synthesis of Poly(ethene-co-1,3-butadiene) with Neodymocene catalysts. Macromolecules 200o, 33, 8521-8523.

(3) Woodman, T. J., Sarazin, Y., Fink, G., Hauschild, K., Bochmann, M. Heterogenized "Ligand-Free" Lanthanide Catalysts for the Homo- and Copolymerization of Ethylene and 1,3Butadiene. Macromolecules 2005, 38, 3060-3067.

(4) Michiue, K., Mitani, M.; Fujita, T. Synthesis of Ethylene or Propylene/1,3-Butadiene Copolymers Possessing Pendant Vinyl Groups with Virtually No Internal Olefins. Catalysts 2015, 20012007.
(5) Pragliola, S.; Costabile, C.; Magrino, M.; Napoli, M.; Longo, $\mathrm{P}$. Ethene/1,3-Butadiene Copolymerization in the Presence of rac- $\left.\left(\mathrm{CH}_{2} \text {-(3-tert-butyl-1-indenyl }\right)_{2}\right) \mathrm{ZrCl}_{2} / \mathrm{MAO}$ Catalytic System: Study of the Polymerization Mechanism by Using ${ }^{13} \mathrm{C}$-Labeled 1,3-Butadiene. Macromolecules 2004, 37, 238-240.

(6) Longo, P.; Napoli, M.; Pragliola, S.; Costabile, C.; Milano, G.; Guerra, G. Butadiene Insertion and Constitutional Units in Ethene Copolymerizations by $C_{2}$-Symmetric Metallocenes. Macromolecules 2003, 36, 9067-9074.

(7) Pragliola, S.; Costabile, C.; Napoli, M.; Guerra, G.; Longo, P. rac- $\left.\left[\mathrm{CH}_{2} \text { (3-tert-butyl-1-indenyl) }\right)_{2}\right] \mathrm{ZrCl}_{2} / \mathrm{MAO}$ in the Copolymerization of Olefins and Dienes. Macromol. Symp. 2006, 234, 128-139.

(8) Pragliola, S.; Costabile, C.; Venditto, V. Ethylene/1,3butadiene cyclocopolymerization catalyzed by zirconocene systems. Eur. Polym. J. 2014, 58, 157-163.

(9) Choo, T. N.; Waymouth, R. M. The Dual-Site Alternating Cyclocopolymerization of 1,3-Butadiene with Ethylene. J. Am. Chem. Soc. 2003, 125, 8970-8971.

(10) Monteil, V.; Spitz, R.; Barbotin, F.; Boisson, C. Evidence of Intramolecular Cyclization in Copolymerization of Ethylene with 1, 3-Butadiene: Thermal Properties of the Resulting Copolymers. Macromol. Chem. Phys. 2004, 205, 737-742.

(11) Llauro, M. F.; Monnet, C.; Barbotin, F.; Monteil, V.; Spitz, R.; Boisson, C. Investigation of Ethylene/Butadiene Copolymers Microstructure by ${ }^{1} \mathrm{H}$ and ${ }^{13} \mathrm{C}$ NMR. Macromolecules 20o1, 34, 6304-6311.

(12) Boisson, C.; Monteil, V.; Thuilliez, J.; Spitz, R.; Monnet, C.; Llauro, M.-F.; Barbotin, F.; Robert, P. Advances and Limits in Copolymerization of Olefins With Conjugated Dienes. Macromol. Symp. 2005, 226, 17-23.

(13) Cortial, G.; Le Goff, X.-F.; Bousquié, M.; Boisson, C.; Le Floch, P.; Nief, F.; Thuilliez, J. Neutral ansa-bis (fluorenyl) silane neodymium borohydrides: synthesis, structural study and behaviour as catalysts in butadiene-ethylene copolymerisation. New J. Chem. 2010, 34, 2290-2297.

(14) Thuilliez, J.; Ricard, L.; Nief, F.; Boisson, F.; Boisson, C. ansa-Bis(fluorenyl)neodymium Catalysts For Cyclocopolymerization of Ethylene with Butadiene. Macromolecules 2009, 42, 3774-3779.

(15) Nsiri, H.; Belaid, I.; Larini, P.; Thuilliez, J.; Boisson, C.; Perrin, L. Ethylene-Butadiene Copolymerization by Neodymocene Complexes: A Ligand Structure/Activity/Polymer Microstructure Relationship Based on DFT Calculations. ACS Catal. 2016, 6, 1028-1036.

(16) Visseaux, M.; Chenal, T.; Roussel, P.; Mortreux, A. Synthesis and X-ray structure of a borohydrido metallocene of neodymium and its use as pre-catalyst in $\mathrm{Nd} / \mathrm{Mg}$ dual-component ethylene and isoprene polymerisations. J. Organomet. Chem. 20o6, 691, 86-92.

(17) Barbier-Baudry, D.; Bonnet, F.; Dormond, A.; Hafid, A.; Nyassi, A.; Visseaux, M. J. Organolanthanides, catalysts for specific olefin-diene copolymerization: access to new materials. Alloys Compd. 2001, 323-324, 592-596.

(18) Jian, Z.; Cui, D.; Hou, Z.; Lib, X. Living catalyzed-chaingrowth polymerization and block copolymerization of isoprene by rare-earth metal allyl precursors bearing a constrainedgeometry-conformation ligand. Chem. Commun. 2010, 46, 30223024.

(19) Li, X.; Nishiura, M.; Hu, L.; Mori, K.; Hou Z. Alternating and Random Copolymerization of Isoprene and Ethylene Catalyzed By Cationic Half-Sandwich Scandium Alkyls. J. Am. Chem. Soc. 2009, 131, 13870-13882.

(20) Wu, C.; Liu, B.; Lin, F.; Wang, M.; Cui, D. cis-1,4-Selective Copolymerization of Ethylene and Butadiene: A Compromise between Two Mechanisms. Angew. Chem., Int. Ed. 2017, 56, 6975-6979. 
(21) Ribeiro R.; Ruivo, R.; Nsiri, H.; Norsic, S.; D’Agosto, F.; Perrin, L.; Boisson, C. Deciphering the Mechanism of Coordinative Chain Transfer Polymerization of Ethylene Using Neodymocene Catalysts and Dialkylmagnesium. ACS Catal. 2016, 6, 851860.

(22) Bogaert, S.; Chenal, T.; Mortreux, A.; Carpentier, J. F. Unusual product distribution in ethylene oligomerization promoted by in situ ansa-chloroneodymocene-dialkylmagnesium systems. J. Mol. Catal. A: Chem. 2002, 190, 207-214.

(23) Olonde, X.; Mortreux, A.; Petit, F.; Bujadoux, K. A useful method for the synthesis of neodymocene homogeneous catalysts for ethylene polymerization. J. Mol. Catal. 1993, 82, 75-82.

(24) Pelletier, J.-F.; Mortreux, A.; Olonde, X.; Bujadoux, K. Synthesis of New Dialkylmagnesium Compounds by Living Transfer Ethylene Oligo- and Polymerization with Lanthanocene Catalysts. Angew. Chem., Int. Ed. Engl. 1996, 35, 1854-1856.

(25) Kempe, R. How to Polymerize Ethylene in a Highly Controlled Fashion? Chem. - Eur. J. 2007, 13, 2764-2773.

(26) Valente, A.; Mortreux, A.; Visseaux, M.; Zinck, P. Coordinative Chain Transfer Polymerization. Chem. Rev. 2013, 113, 3836-3857.

(27) Hou, Z. M.; Wakatsuki, Y. Recent developments in organolanthanide polymerization catalysts. Coord. Chem. Rev. 2002, 231, 1-22.

(28) Zhang, W.; Wei, J.; Sita, L. R. Living Coordinative ChainTransfer Polymerization and Copolymerization of Ethene, ROlefins, and R, $\omega$-Nonconjugated Dienes using Dialkylzinc as "Surrogate" Chain-Growth Sites. Macromolecules 20o8, 41, 78297833.

(29) Sita, L. R. Ex Uno Plures (“Out of One, Many”): New Paradigms for Expanding the Range of Polyolefins through Reversible Group Transfers. Angew. Chem. Int. Ed. 2009, 48, 2464-2472.

(30) Mazzolini, J.; Espinosa, E.; D’Agosto, F.; Boisson C. Catalyzed chain growth (CCG) on a main group metal: an efficient tool tofunctionalize polyethylene. Polym. Chem. 2010, 1, 793-80o.

(31) German, I.; Kelhifi, W.; Norsic, S.; Boisson, C.; D’Agosto, F. Telechelic Polyethylene from Catalyzed Chain-Growth Polymerization. Angew. Chem., Int. Ed. 2013, 52, 3438-3441.

(32) Roca-Sabio, A.; Regueiro-Figueroa, M.; Esteban-Gomez, D.; De Blas, A.; Rodriguez-Blas, T.; Platas-Iglesias, C. Density functional dependence of molecular geometries in lanthanide (III) complexes relevant to bioanalytical and biomedical applications. Comput. Theor. Chem. 2012, 999, 93-104.

(33) Castro, L.; Kirillov, E.; Miserque, O.; Welle, A.; Haspeslagh, L.; Carpentier, J. F.; Maron, L. Are Solvent and Dispersion Effects Crucial in Olefin Polymerization DFT Calculations? Some Insights from Propylene Coordination and Insertion Reactions with Group 3 and 4 Metallocenes. ACS Catal. 2015, 5, 416-425.

(34) Perrin, L.; Eisenstein, O.; Maron, L. Chemoselectivity in $\sigma$ bond activation by lanthanocene complexes from a DFT perspective: reactions of $\mathrm{Cp}_{2} \mathrm{LnR}\left(\mathrm{R}=\mathrm{CH}_{3}, \mathrm{H}, \mathrm{SiH}_{3}\right)$ with $\mathrm{SiH}_{4}$ and $\mathrm{CH}_{3}-\mathrm{SiH}_{3}$. New J. Chem. 2007, 31, 549-555.

(35) Perrin, L.; Bonnet, F.; Chenal, T.; Visseaux, M.; Maron, L. A Joint Experimental/Theoretical Investigation of the Statistical Olefin/Conjugated Diene Copolymerization Catalyzed by a Hemi-Lanthanidocene $\left[\left(\mathrm{Cp}^{*}\right)\left(\mathrm{BH}_{4}\right) \mathrm{LnR}\right]$. Chem. - Eur. J. 2010, 16, $11376-11385$.

(36) Perrin, L.; Carr, K. J. T.; McKay, D.; McMullin, C. L.; Macgregor, S. A.; Eisenstein O. Modelling and Rationalizing Organometallic Chemistry with Computation: Where Are We? Struct. Bonding 2015, 167, 1-37.

(37) Kefalidis, C. E.; Castro, L.; Perrin, L.; Del Rosal, I; Maron, L. New perspectives in organolanthanide chemistry from redox to bond metathesis: insights from theory. Chem. Soc. Rev. 2016, 45, 2516-2543.

(38) Talarico, G.; Blok, A. N. J.; Woo, T. K.; Cavallo, L. Comparison of ab Initio and DFT Methods for Studying Chain Propagation and Chain Termination Processes with Group 4 Polymerization Catalysts. 1. The ansa-Bis(cyclopentadienyl)zirconium Catalyst. Organometallics 2002, 21, 4939-4949.

(39) Muñoz-Escalona, A.; Ramos, J.; Cruz, V.; MartínezSalazar, J. Effect of a Second Ethylene Molecule on the Insertion of Ethylene in Zirconocene Catalyst Systems: A QM Semiempirical Study. J. Pol. Sci. Part A Pol. Chem. 2ooo, 38, 571-582.

(40) Wolpers, A.; Vana, P. UV Light as External Switch and Boost of Molar-Mass Control in Iodine-Mediated Polymerization. Macromolecules 2014, 47, 954.

(41) Yamago, S. Precision Polymer Synthesis by Degenerative Transfer Controlled/Living Radical Polymerization Using Organotellurium, Organostibine, and Organobismuthine ChainTransfer Agents. Chem. Rev. 2009, 109, 5051-5068.

(42) Calhorda, M. J.; Gonçalves, I. S.; Herdtweck, E.; Romão, C. C.; Royo, B.; Veiros, L. F. Exocyclic Coordination of the $\eta^{3-}$ Fluorenyl Anion: Experimental and Theoretical Study. Organometallics 1999, 18, 3956-3958.

(43) Rodrigues, A.-S.; Kirillov, E.; Lehmann, C. W; Roisnel, T.; Vuillemin, B.; Razavi, A.; Carpentier J.-F. Allyl ansa-Lanthanidocenes: Single-Component, Single-Site Catalysts for Controlled Syndiospecific Styrene and Styrene-Ethylene (Co)Polymerization. Chem. Eur. J. 2007, 13, 5548-5565. 
For Table of Content Only

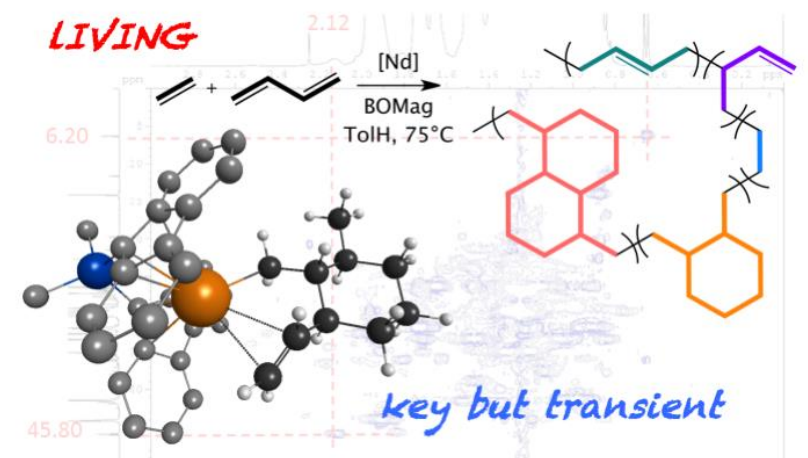

